\title{
Numerical analysis of droplet atomization in wet electrostatic precipitator based on computational particle-fluid dynamics
}

\author{
Feng Liu \\ Tianjin SDIC Jinneng Electric Power Co., Ltd., Tianjin 300480, China
}

Corresponding Author Email: liulf6677@163.com

https://doi.org/10.18280/ijht.360129

Received: 9 September 2017

Accepted: 22 November 2017

\section{Keywords:}

wet electrostatic precipitator, computational particle-fluid dynamics $(C P F D)$, numerical simulation, droplet atomization

\begin{abstract}
This paper aims to develop a cost-efficient simulation method for droplet atomization in wet electrostatic precipitator. Under the combined effects of multiple nozzles, the computational particle-fluid dynamics (CPFD) method was employed to simulate the atomization process, because it can settle complex particle flow problems with a small number of grids. Specifically, the droplet pattern, flue gas speed distribution and flue gas pressure distribution in the precipitator were investigated at the inlet gas speeds of $1 \mathrm{~m} / \mathrm{s}, 2 \mathrm{~m} / \mathrm{s}$ and $3.5 \mathrm{~m} / \mathrm{s}$. It is found that the droplet ejection changes the flow of the flue gas; the low inlet speed facilitates the formation of the liquid film; the greater the inlet speed, the closer the peak position of flue gas speed moves towards the top. The results shed new light on the optimization of wet-process electric dedusting.
\end{abstract}

\section{INTRODUCTION}

In recent years, fine dust pollutants have raised concerns due to the frequent hazy weather in China. Power plants across the country are resorting to various techniques to reduce fine dust emissions. One of the relatively effective technique is to utilize the wet electrostatic precipitator [1,2]. Compared to ordinary electrostatic precipitator, the wet electrostatic precipitator does well in reducing pollutants like acid mist, fine dust and heavy metals $[3,4]$. The excellent performance is attributable to the combination between fine droplets and pollutants during the formation of the water film, which makes it easier to remove the pollutants. This means the trace of fine droplets directly bears on the pollutant removal efficiency.

Nevertheless, the size of atomized droplets in the wet electrostatic precipitator are so small that it is hard to test their flow process [5 7]. Thus, there are only a few reports on the behaviour of atomized droplets. For example, Xu Licheng and Sun Heping [8] described the dust removal by spray with the theory of cloud condensation nuclei, pointing out that the optimal removal effect appears when the atomized droplets share the same size with dusts. Zhu Jinlin [9-11] simulated the two-nozzle spray process by computational fluid dynamics (CFD), aiming to disclose the impact of nozzle structure on the removal effect. Wu Geping [12] numerically analysed the secondary atomization when two droplets collide near the nozzle. Focusing on atomized spray pressure, Ji Hong [13] discussed the effect of initial injection angle on the atomization performance. Selvam R.P., Lin L. and Ponnappan R. [14] explored the boiling spray atomization process through continuous phase and discrete phase coupling calculation.

In spite of the valuable findings, all of the above studies require extremely expensive lab equipment. To solve the problem, this paper examines the flue gas emission in Tianjin SDIC Jinneng Electric Power Co., Ltd., and probes deep into the wet-process electric dedusting transformation based on the numerical calculation platform of Northeast Electric Power
University. Under the combined effects of multiple nozzles, the computational particle-fluid dynamics (CPFD) method was employed to simulate the atomization process. The simulation results reveal the movement of atomized droplets inside the wet electrostatic precipitator at different inlet flue gas speeds.

\section{METHODOLOGY}

Facing the two-phase flow problem [15], the traditional CFD method [16] cannot handle the large number of particles well. By contrast, the CPFD approach can solve this problem rapidly and with good convergence.

As a numerical strategy, the CPFD [17] offers a EulerLagrange coupling solution to the 3D motion of particles in the fluid. This strategy is more efficient than other multiphase flow numerical methods, thanks to its unique concept of particle group (i.e. the group of particles with similar features). In the flow field, the particle groups collide with each other under the gravity, friction and particle forces. In the CPFD, there are separate control equations for gas phase motion and particle phase motion. The equations for gas phase motion can be expressed as [18-20]:

$$
\begin{aligned}
& \frac{\partial}{\partial t}\left(\rho_{g} \theta_{g}\right)+\nabla \bullet\left(\rho_{g} \theta_{g} v_{g}\right)=S_{g} \\
& \frac{\partial}{\partial t}\left(\rho_{g} \theta_{g} v_{g}\right)+\nabla \bullet\left(\rho_{g} \theta_{g} v_{g}\right)=-\nabla P+\nabla \bullet \theta_{g} \tau_{g}+\rho_{g} \theta_{g} g-F
\end{aligned}
$$

where $\theta_{g}$ is the ratio of the volume occupied by the gas phase; $\rho_{g}, v_{g}, \tau_{g}, S_{g}, P$ and $g$ are the material density, the gas speed, the gas stress tensor, the gas source, the air pressure and the 
acceleration of gravity, respectively; $F$ is the viscous force between the two phases:

$$
F=\iint f m\left(4.5 \frac{\mu_{g}}{\rho_{p} r_{p}^{2}} f_{b}\left(v_{g}-v_{p}\right)-\frac{\nabla P}{\rho_{p}}\right) d m d v
$$

where $\mu_{g}$ is the dynamic viscosity of gas; $r_{p}$ is the particle radius; $v_{p}$ is the particle phase speed; $\rho_{p}$ is the particle phase density; $f$ is the probability distribution function.

The drag force was depicted by the Wen-Yu-Ergun model, which was developed from Wen-Yu model and Ergun model through linear transformation. Hence, $f_{b}$ can be determined by the drag coefficient:

$$
\left\{\begin{array}{l}
f_{b}=f_{w}, \theta_{p}<0.75 \theta_{c p} \\
f_{b}=f_{w}+\frac{\theta_{p}-0.75 \theta_{c p}}{0.1 \theta_{c p}}\left(f_{e}-f_{w}\right), 0.75 \theta_{c p} \leq \theta_{p} \leq 0.85 \theta_{c p} \\
f_{b}=f_{\mathrm{e}}, \theta_{p}>0.85 \theta_{c p}
\end{array}\right.
$$

where $\theta_{c p}$ is the particle state in a compacted volume fraction; $f_{w}$ and $f_{s}$ are obtained from Wen-Yu model and Ergun model, respectively.

To calculate the particle collision, the normal stress of particles can be expressed as:

$$
\tau_{p}=\frac{P_{s} \theta_{p}^{\gamma}}{\max \left[\left(\theta_{c p}-\theta_{p}\right), \varepsilon\left(1-\theta_{p}\right)\right]}
$$

where $P_{s}$ is a positive constant; $\gamma$ is the singular point elimination coefficient. The value of the coefficient is small and falls in the range of $[1.2,5]$

\section{OBJECT CONSTRUCTION}

In the wet electrostatic precipitator, the charged particles are generated by negative high-voltage corona discharge. Then, the dusts of flue gas are charged through collision with these particles. The charged dusts will rush towards the collecting electrode and get trapped under the air flow and electric field. Meanwhile, a film is formed on the dust collecting plate in the atomizer system, so that the dusts can flow with water under the action of gravity. Finally, the sewage will enter the circulation system or the sewage treatment system through the sewage outlets. The main structure of the wet electrostatic precipitator is illustrated in Figure 1.

The primary goal of our research is to identify the movement pattern of droplets in the dust collector at different inlet wind speeds. However, it is difficult to calculate the charge quantity of droplets, for many droplets are polymerized during the movement after atomization. For simplification, the charge effect of the electric field on the droplet was neglected, that is, the droplets were assumed to be immune from the electric field force.

The size of the test equipment was determined based on a real wet electrostatic precipitator. The fluid domain between two rows of dust collecting plates was taken as a computing unit, with the aim to lower the computing load. Each computing unit is $9.6 \mathrm{~m}$ long, $6 \mathrm{~m}$ tall, $0.455 \mathrm{~m}$ away from each side of the collection plate, and $0.5 \mathrm{~m}$ away from the glass baffle on each side of the test bench. The inlet pressure and nozzle speed were set to $95,700 \mathrm{~Pa}$ and $25 \mathrm{~m} / \mathrm{s}$, respectively, and the total mass flow rate to $0.1 \mathrm{~kg} / \mathrm{s}$.

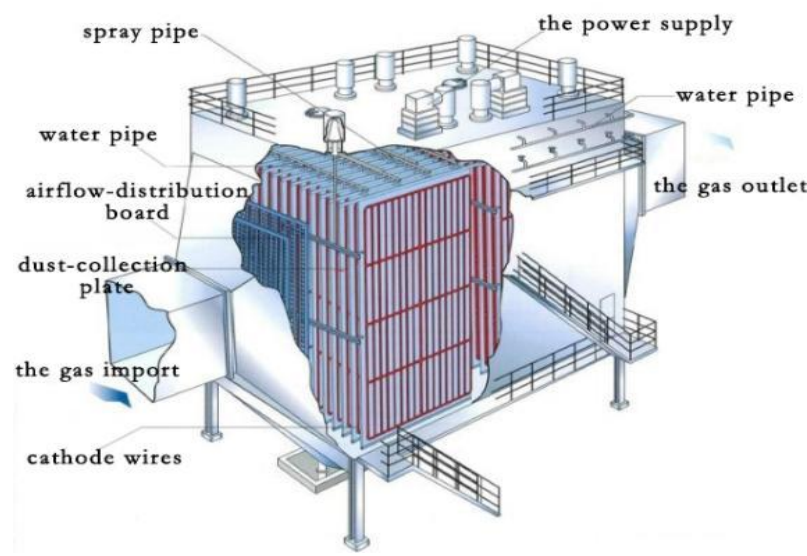

Figure 1. The structure of wet electrostatic precipitator

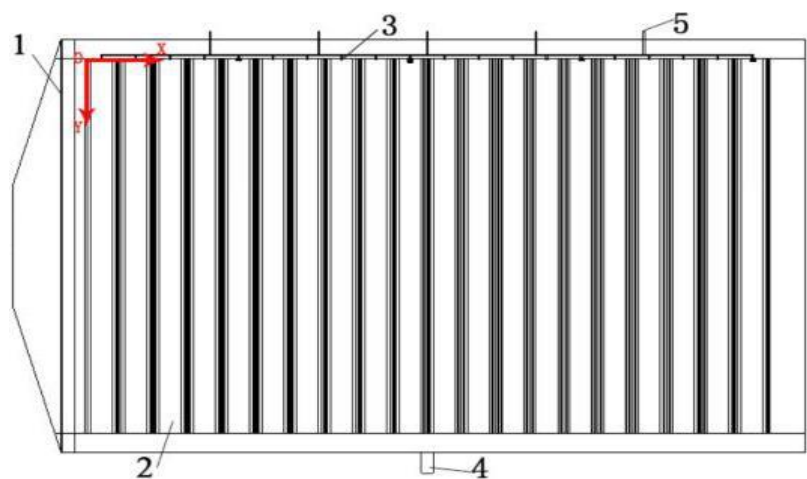

1-Uniform airflow plate, 2-dust-collecting plate, 3-spray nozzle, 4-sewage effluent, 5-Atomized water inlet pipe, Point $\mathrm{O}$ is the coordinate origin; $\mathrm{x}$-axis is the horizontal direction; $y$-axis is the vertical direction

Figure 2. The structure of dust collecting plates

After atomization, the droplets are extremely small, making it difficult for them to fall off after leaving the nozzle. That is why the particle group method of the CPFD was adopted to polymerize these fine droplets. In our research, the particle size distribution is selected according to nozzle atomization. Considering the features of the atomizing noddle, the cumulative volume distribution curve was drawn to describe the droplet size distribution during the atomization process [21]. The curve reflects the ratio of the amount/volume occupied by the droplets of a certain diameter.

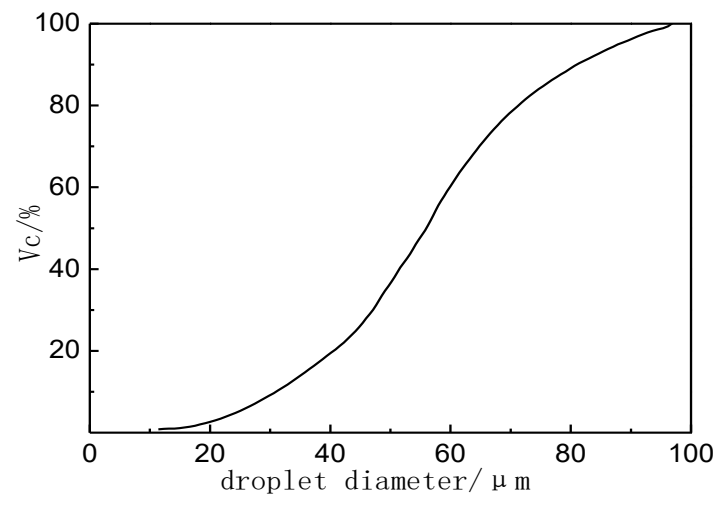

Figure 3. Cumulative volume distribution curve 
The CPFD method can also enhance the efficiency of computing the complex motion of spray droplets in the wet electrostatic precipitator. By the CPDF method, the computing domain was meshed into a number of orthogonal grids. Each grid is a virtual rectangle. The grids at the boundaries were fitted to the irregular edges of the computing domain.

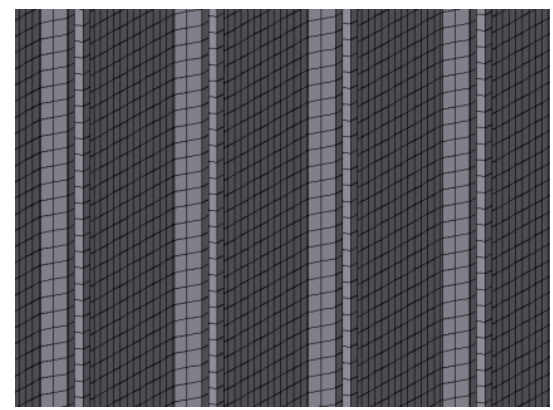

Figure 4. The distribution of the mesh

\section{SIMULATION RESULTS}

\subsection{Droplet distribution}

Figure 5 presents the droplet motion in the precipitator at different flue gas inlet speeds $(1 \mathrm{~m} / \mathrm{s}, 2 \mathrm{~m} / \mathrm{s}$ and $3.5 \mathrm{~m} / \mathrm{s})$ at the fifth second. It can be seen that the droplet pattern hinges directly on the inlet speed of flue gas, and a blank are appeared at the outlet. At the inlet speed of $1 \mathrm{~m} / \mathrm{s}$, the drops could easily gather near the collecting plate, leaving a large blank area. With the increase in the inlet speed, the droplet on the plate grew larger, and the blank area got smaller. This is because the flow direction and speed changed, as the gas receives the kinetic energy of ejected droplets. Moreover, the initial kinetic energy of the gas varied with the inlet speeds. The speed of droplets dropped sharply once they hit the collecting plate. Thus, the influence of flue gas is positively correlated with the distance along the y-axis.
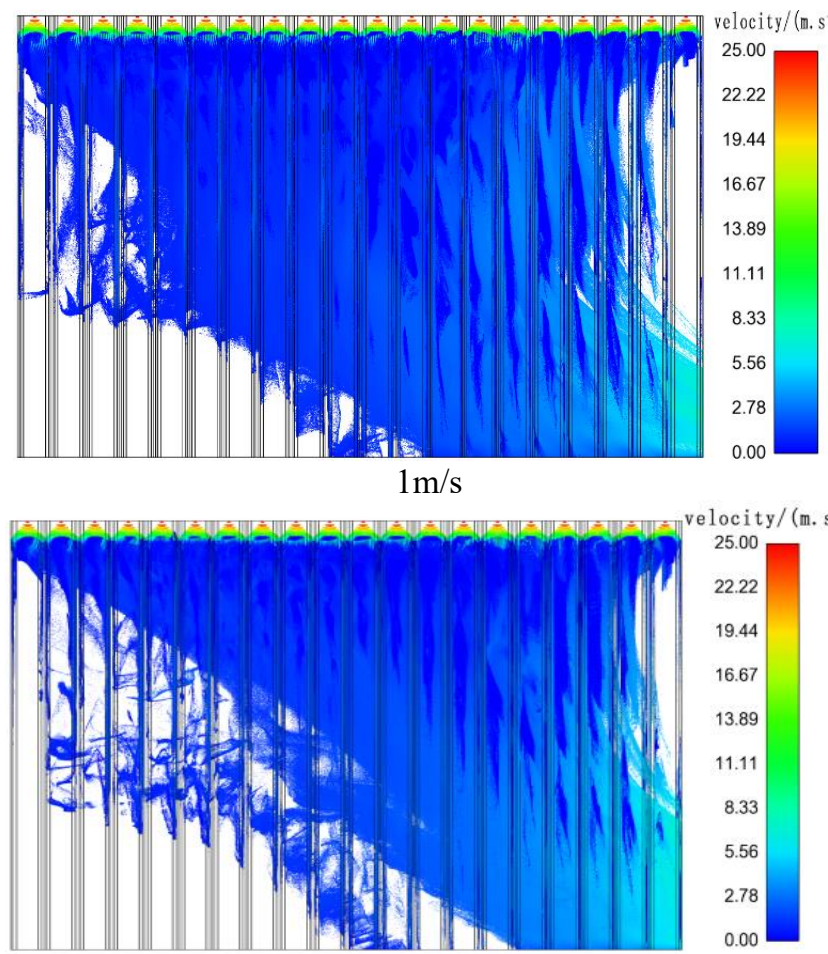

elocity/(m. s

25.00
22.22
19.44
16.67
13.89
11.11
8.33
5.56
2.78
0.00

$2 \mathrm{~m} / \mathrm{s}$

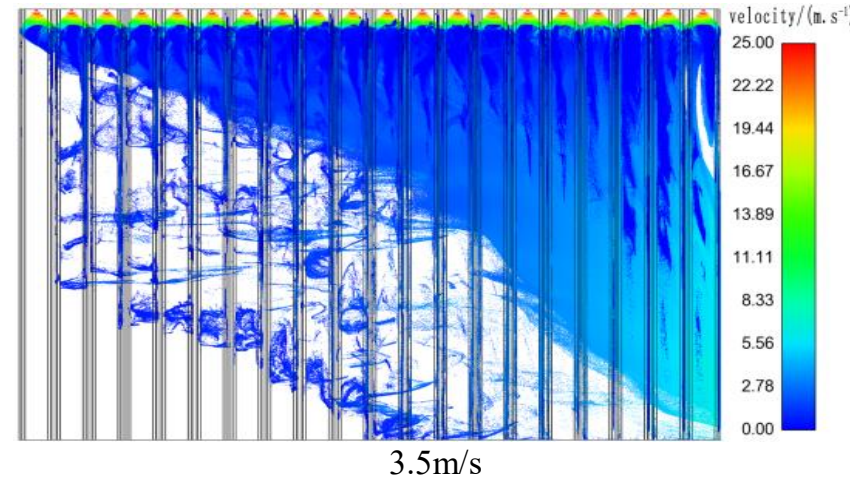

Figure 5. Droplet distribution at different inlet speeds

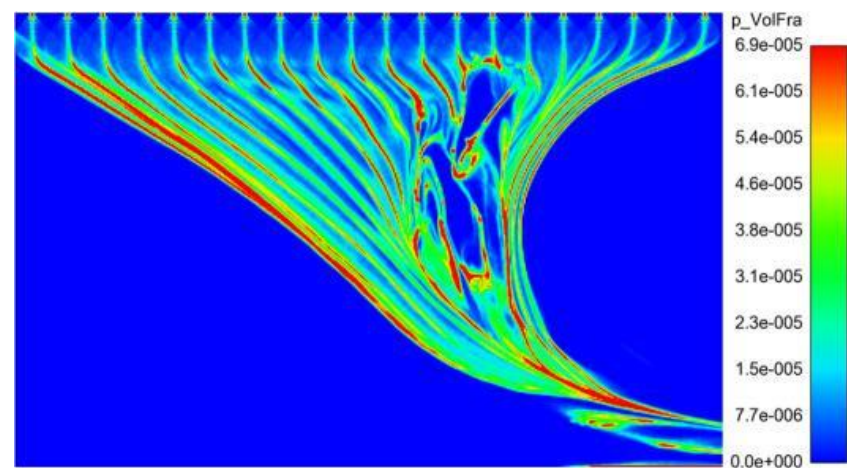

$1 \mathrm{~m} / \mathrm{s}$

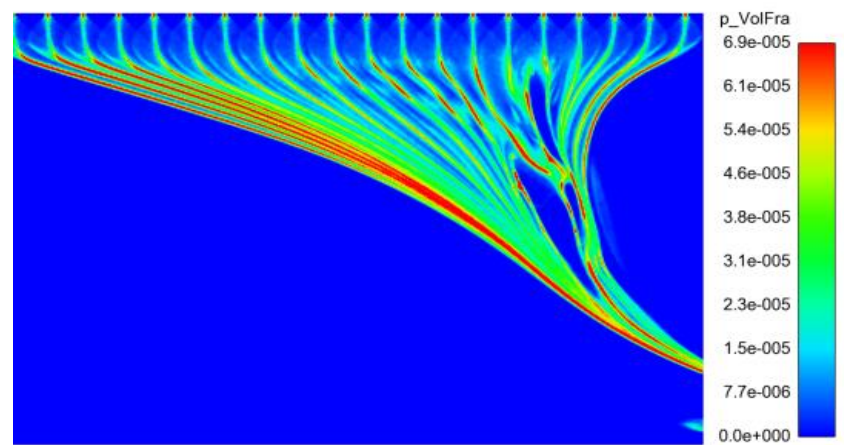

$2 \mathrm{~m} / \mathrm{s}$

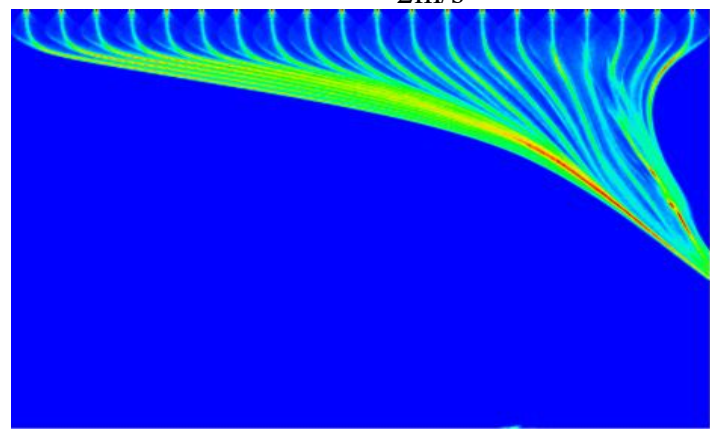

P_VolFra

$3.5 \mathrm{~m} / \mathrm{s}$

Figure 6. Distribution of droplet concentration in the central section

Figure 6 displays the distribution of droplet concentration in the central section of the flow field. When the inlet flue gas flowed at $1 \mathrm{~m} / \mathrm{s}$, the blank area appeared between the $14^{\text {th }}$ nozzle and the outlet. With the increase in the inlet speed, the bank area moved closer to the outlet and shrank in size. The droplet concentration in the fluid space was relatively high at a low inlet speed. By contrast, the droplets from the central section arrived near the top of the outlet at a high inlet speed, such that only a small area of the collecting plate was covered by the droplets. 


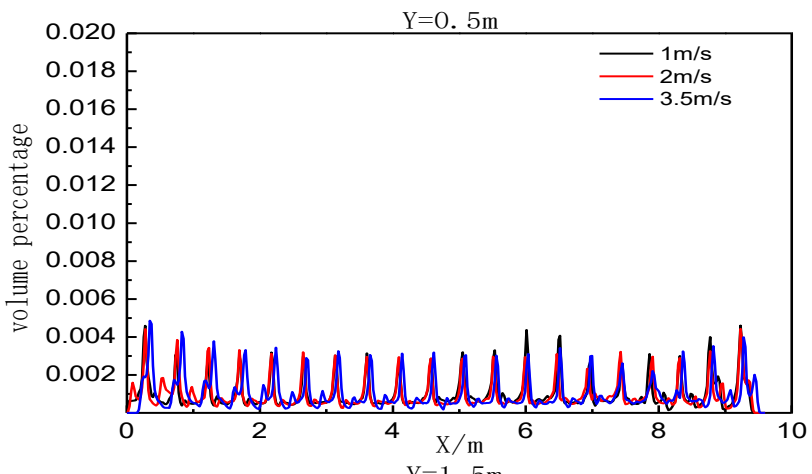

other two conditions. The reason is that the blank area shrinks at higher inlet speeds. The result is consistent with that of Figure 6.

\subsection{The distribution of velocities and pressure}
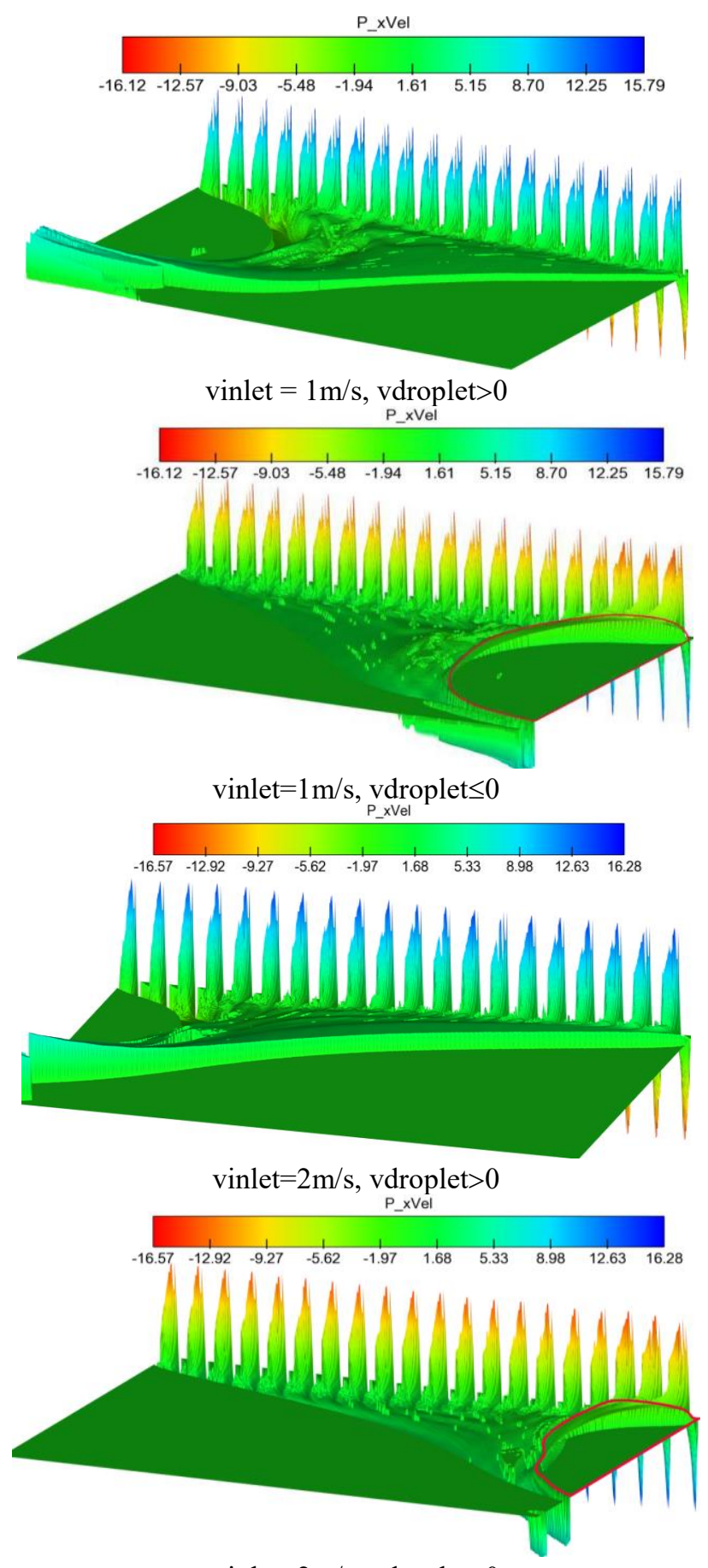

vinlet $=2 \mathrm{~m} / \mathrm{s}$, vdroplet $\leq 0$

Figure 7 shows the volume fraction of droplets at different positions in the flow field and different inlet speeds. Under the constant $\mathrm{x}$-coordinate, the droplet concentration had basically the same value and trend at different inlet speeds and the ycoordinate of 0.5 . The 20 peaks in the figure corresponded with the 20 nozzles, indicating that the droplets at this height do not diffuse due to the high kinetic energy. In this case, the droplet speed plays a dominant role. Whichever the height, the smaller the inlet speed, the faster the droplet volume faction dropped to zero in the x-direction. In other words, the inlet speed is negatively correlated with the area of zero droplet volume fraction. In addition, the droplet volume fraction near the inlet at the inlet speed of $3 \mathrm{~m} / \mathrm{s}$ was higher than that at the

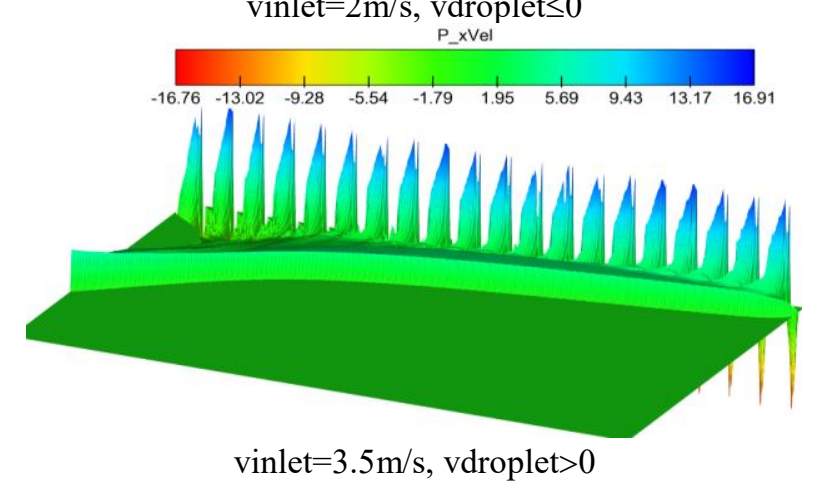




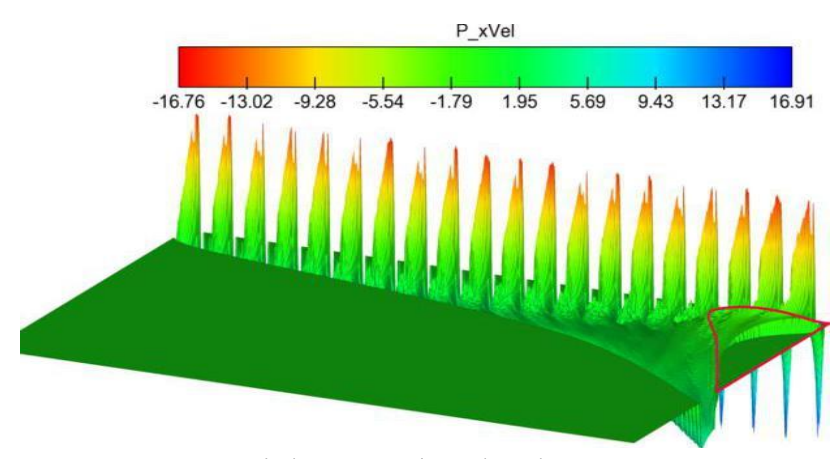

vinlet $=3.5 \mathrm{~m} / \mathrm{s}$, vdroplet $\leq 0$

Figure 8. Droplet speed component along the $\mathrm{x}$-axis
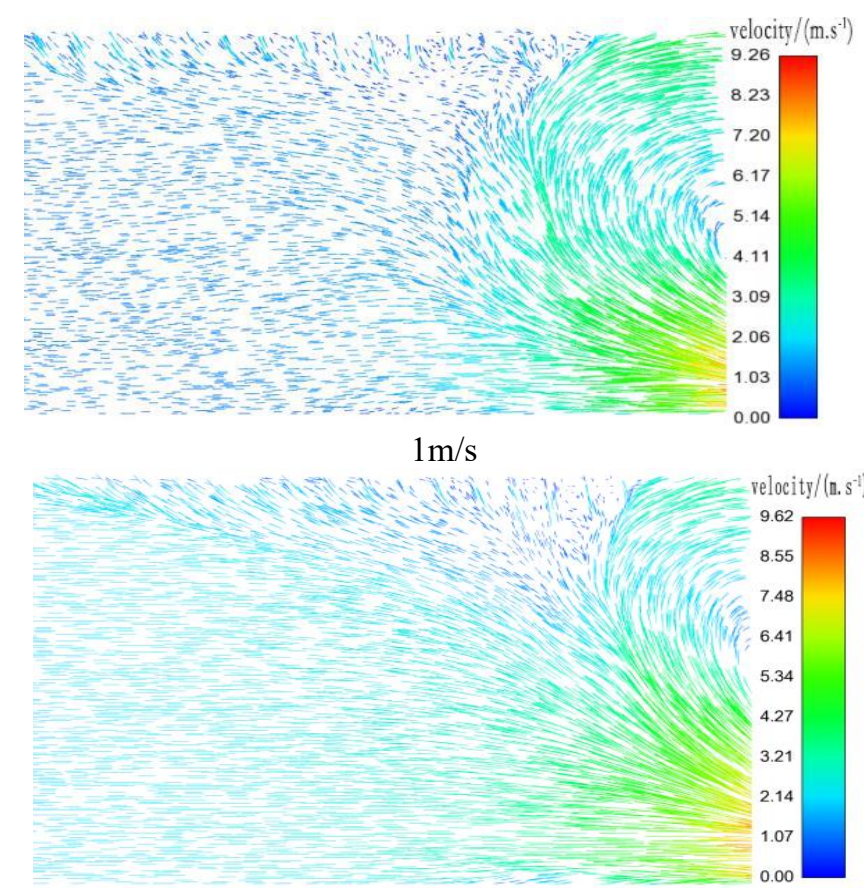

$2 \mathrm{~m} / \mathrm{s}$

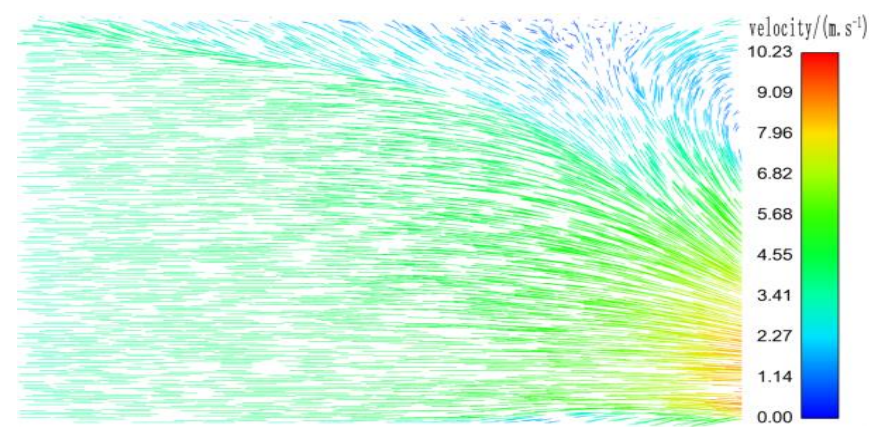

$3.5 \mathrm{~m} / \mathrm{s}$

Figure 9. Flue gas speed distribution and speed vectors

The droplet speed component along the $\mathrm{x}$-axis was plotted with the flow direction of flue gas as the positive direction (Figure 8). It can be seen that the droplets leaving the nozzle may or may not move along the positive direction. The positive and negative speed components are symmetrical with respect to zero. When the droplets were far from the nozzle, the speed component of some droplets turned negative along the $\mathrm{x}$-axis. In this case, these droplets moved towards the reverse direction, creating a circumfluence area in the flow field. This area is marked in red in Figure 8. Obviously, the size of the circumfluence area is negatively correlated with the inlet speed.

Figure 9 is records the flue gas speed distribution and speed vectors at different inlet speeds at the $5^{\text {th }}$ second. When the flue gas flows into the precipitator, the direction of the gas shifted and the speed increased drastically under the injection effect. The peak speed of the flue gas appeared near the bottom of the outlet, because the gas received kinetic energy from the atomized droplets sprayed out of the nozzle. Similar to Figure 8 , reflux occurred near the top of the outlet, which drove the droplets away, after the flue gas hit the boundary of the circumfluence area. This explains the origin of the blank areas in Figures 5 and 6. Besides, it is observed that the area of positive speed is positively with the inlet speed.

The above analysis shows obvious changes to the speed in the horizontal direction. Next, the gas speeds in this direction were compared at six different heights along the y-axis (Figure 10).

As can be seen from Figure 10, the gas speeds changed in a similar pattern at different inlet speeds. For the heights of $0.5 \mathrm{~m}$ and $1.5 \mathrm{~m}$, the flue gas speeds first declined and then increased at different inlet speeds; the speeds reached the lowest point after the gas entered the blank area, and then exhibited a rapid increase. The flue gas speed at the outlet of the blank area is negatively correlated with the inlet speed. Coupled with Figure 9, the negative correlation can be explained by the following factors: the gas speed points to the opposite direction of the flow, the reflux is reformed in the blank area, and the gas receives the kinetic energy from spray nozzles.
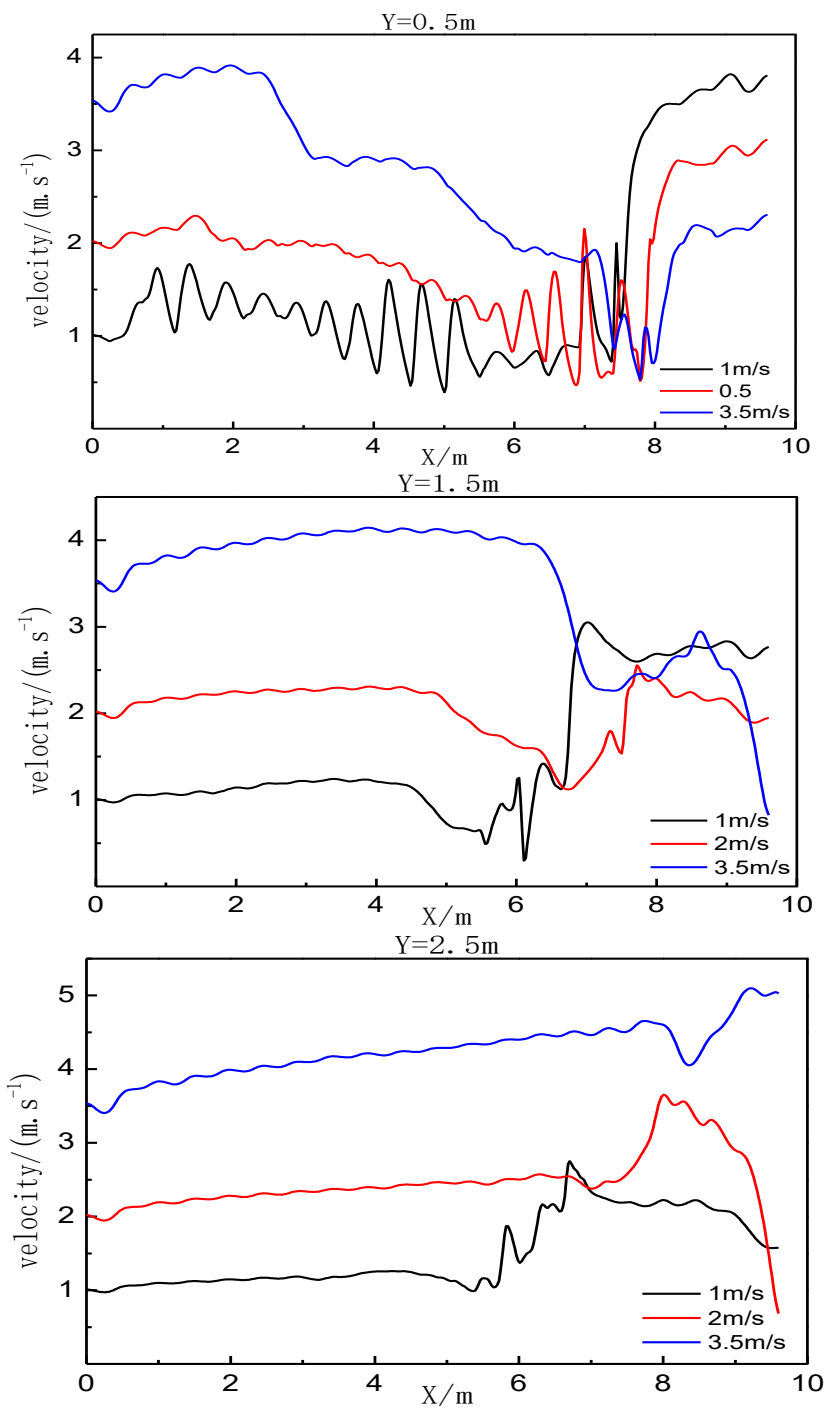

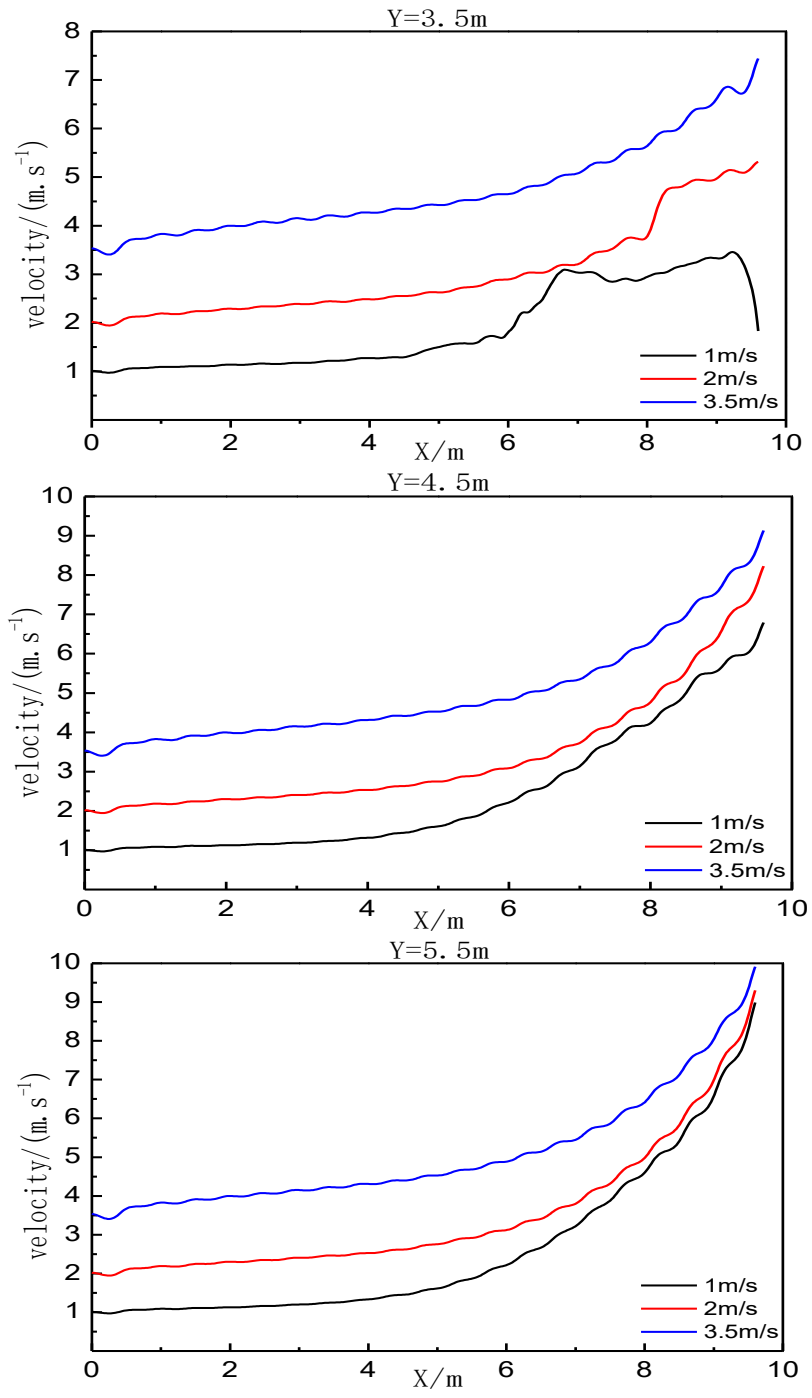

Figure 10. Flue gas speeds at different heights

Similar results were obtained for the height of $2.5 \mathrm{~m}$ and the inlet speeds of $1 \mathrm{~m} / \mathrm{s}$ and $2 \mathrm{~m} / \mathrm{s}$. When the inlet speed was $3.5 \mathrm{~m} / \mathrm{s}$ at the height of $2.5 \mathrm{~m}$, the gas was still affected by the reflux despite the absence of the blank area; in this case, the gas speed also dropped before rising, and the flue gas outlet speed was faster than it was at the inlet speeds of $1 \mathrm{~m} / \mathrm{s}$ and $2 \mathrm{~m} / \mathrm{s}$. For the other heights, the gas speed increased markedly as the gas moved closer to the bottom of the outlet, and peaked at the outlet bottom.

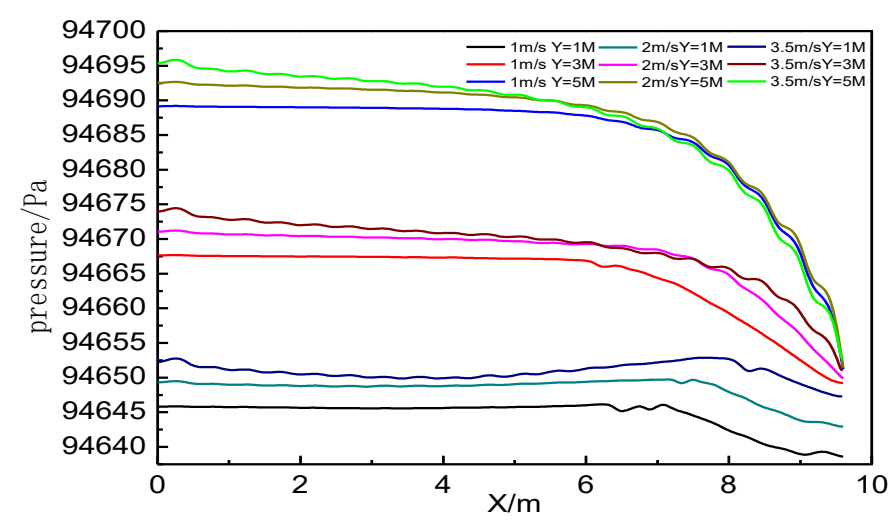

Figure 11. Static pressures at different heights and inlet speeds
Figure 11 presents the static pressures at three heights and different inlet speeds. For the same height, the pressure is positively correlated with the inlet speed; the pressure obeys the same distribution at different inlet speeds; the pressure decreased along the x-direction. For the same inlet speed, the pressure increased with the height, because the gas along the $y$-axis was accelerated by the high-speed atomized droplets. Thus, the flue gas pressure decreased as the gas moved closer to the nozzles. The inverse is also true.

\section{CONCLUSION}

Based on the CPFD method, this paper simulates the droplet motion in the wet electrostatic precipitator at different inlet gas speeds. The features of the two-phase flow in the precipitator were discussed, including droplet pattern, flue gas speed distribution and flue gas pressure distribution. The main conclusions are as follows.

First, the droplet ejection changes the flow of the flue gas. The high-speed droplets from the nozzle speed up the flue gas at the outlet, and create a flue gas circumfluence area near the top of the outlet. Once the droplets move to another direction, a blank area will come into being. The size of the blank area is negatively correlated with the inlet speed.

Second, compared to high inlet speed, the low inlet speed polymerizes the droplets near the collecting plate, increases the droplet volume fraction, and facilitates the formation of the liquid film.

Third, the circumfluence area near the outlet at the inlet speed of $1 \mathrm{~m} / \mathrm{s}$ is larger than that at $2 \mathrm{~m} / \mathrm{s}$ or $3.5 \mathrm{~m} / \mathrm{s}$. Meanwhile, the flue gas speed along the $\mathrm{x}$-direction increases with the inlet speed and peaks at the bottom of the outlet. The greater the inlet speed, the closer the peak position of flue gas speed moves towards the top.

\section{REFERENCES}

[1] Li L. (2008). Experimental study on submicron particles agglomeration enhanced by chargered droplets. Shandong University.

[2] Chen P. (2002). Research of wet electrostatic precipitator. Liaoning Technical University.

[3] Wang Y. (2014). Uniformity of water film and enhancement of fine particles removal in wet electrostatic precipitator. Zhejiang University.

[4] Chang J, Dong Y, Wang Z, et al. (2011). Removal of sulfuric acid aerosol in a wet electrostatic precipitator with single terylene or polypropylene collection electrodes. Journal of Aerosol Scinece 42(8): 544-554.

[5] Zhou G, Cheng WM, Nei W, et al. (2012). Extended theoretical analysis of jet and atomization under highpressure spraying and collecting dust mechanism of droplet. Journal of Chongqing University 35(3): 121- 126.

[6] Chen B, Guo LJ, Zhang XM, et al. (2002). Experimental research on the characteristic of the spray atomization. Journal of Engineering Thermophysics 22(2): 237-240.

[7] Wei MR, Wen H, Liu YC, et al. (2005). Modeling Study on Droplets Collision in Spray Process. Transactions of CSICE 23(6): 518-523.

[8] Xu LC, Sun HP. (1994). Theory and application of collection dust on mist spraying. Ventilation Dust 4 (4): 16-18. 
[9] Zhu JL, Xie J, et.al. (2014). Numerical simulation and test on nozzle spraying uniformity in evaporative condenser. Transactions of the Chinese Society of Agricultural Engineering 30(19): 38-47.

[10] Chen H. (2016). Analysis of numerical simulation of wading landslide in Three Gorges Reservoir area based on Outang Landslide. Mathematical Modelling of Engineering Problems 3(2): 71-74. https://doi.org/ 10.18280/mmep.030205

[11] Zhang W, Du XZ, Yang LJ, Yang YP. (2016). Research on performance of finned tube bundles of indirect aircooled heat exchangers. Mathematical Modelling of Engineering Problems 3(1): 47-51. https://doi.org/ 10.18280/mmep.030108

[12] Wu GP, Gong J, et.al. (2016) Subsequent development of droplet collision in impinging stream. Journal of Jiangsu University 37(5): 525-529, 547.

[13] Ji H, Wu Z, et.al. (2016). Atomization characteristics of spiral core nozzle based on DPM. Journal of Lanzhou University of Technology 42(3): 51-56.

[14] Selvam RP, Lin L, Ponnappan R. (2006). Direct simulation of spray cooling: Effect of vapor bubble growth and liquid droplet impact on heat transfer. International Journal of Heat and Mass Transfer 49(23): 4265-4278.

[15] Bounaouara H, Ettouati H, Ticha HB, Mhimid A, Sautet JC. (2015). Numerical simulation of gas-particles two phase flow in pipe of complex geometry: Pneumatic conveying of olive cake particles toward a dust burner.
International Journal of Heat and Technology 33(1): 9198. https://doi.org/ 10.18280/ijht.330114

[16] Rafiee SE, Sadeghiazad MM. (2016). Three-dimensional CFD simulation of fluid flow inside a vortex tube on basis of an experimental model- the optimization of vortex chamber radius. International Journal of Heat and Technology 34(2): 236-244. https://doi.org/ 10.18280/ijht.340212

[17] Wang J, Yang L, Xu ZZ, Zhong R, Wu GH, Zhang XX, Li XJ, Xie YH, Zhu T. (2016). Numerical simulation on underwater explosion in small-sized containers. Mathematical Modelling of Engineering Problems 3(3): 151-156. https://doi.org/ 10.18280/mmep.030307

[18] Zhao S, Xu ZY, Zhong JC, Sun KX. (2016). The application of shaped charge blasting technology in open-pit mine. Mathematical Modelling of Engineering Problems 3(2): 91-95. https://doi.org/ 10.18280/mmep.030209

[19] Snider DM. (2001). An Incompressible ThreeDimensional multiphase particle-in-cell model for dense particle flows. Journal of computational physics 70(2): 523-549.

[20] Qiu GZ, Ye JM, Wang HG, et al. (2016). CPFD simulation of gas-solids flow in annular combustion chamber of large-scale circulating fluidized bed. Journal of University of Chinese Academy of Sciences 33(2): 18222.

[21] Cao JM. (2005). Spray. Beijing: China Machine PRESS, $81-83$ 